\title{
Budaya Organisasi, Fleksibilitas Kerja, dan Feedback Terhadap Prestasi Kerja Transportasi GOJEK di Palembang
}

\author{
Moh Oktaviannur \\ Universitas Bandar Lampung, Indonesia \\ Email corresponding author: oktavianur@ubl.ac.id
}

\begin{abstract}
ABSTRAK
Tujuan menganalisis pengaruh budaya organisasi, fleksibilitas kerja, dan umpan balik terhadap kinerja kerja ojek online (Gojek). Jenis penelitian kuantitatif deskriptif. Populasi adalah Pengemudi Gojek di Palembang. Sampelnya adalah 110 Pengemudi Gojek Kota Palembang. Data diperoleh dari kuesioner dengan teknik pengambilan sampel accidental sampling. Teknik analisis data regresi linier berganda. Hasil uji t menunjukkan bahwa budaya organisasi berpengaruh positif dan signifikan terhadap prestasi kerja angkutan ojek online (gojek). Umpan balik berpengaruh positif dan signifikan terhadap prestasi kerja angkutan ojek online (Gojek). Fleksibilitas kerja berpengaruh positif dan signifikan terhadap prestasi kerja angkutan ojek online (Gojek). Hasil koefisien determinasi menunjukkan bahwa variabel fleksibilitas kerja, umpan balik, dan budaya organisasi mempunyai kontribusi sebesar $46,2 \%$ terhadap variabel prestasi kerja angkutan ojek online (gojek).
\end{abstract}

Kata Kunci: Organizational culture, work flexibility, feedback

\section{PENDAHULUAN}

Segala aktivitas atau proses yang ada di perusahaan maupun organisasi, kurang berjalan dengan baik apabila perusahaan atau organisasi itu kekurangan adanya sumber daya khususnya manusia untuk menjalankan proses apapun berkaitan dengan perusahaan atau organisasi tersebut. Perusahaan harus mempunyai sekaligus menerapkan strategi terkait dengan tujuan mempertahankan dan mengembangkan ketersediaan sumber daya manusia sesuai kriteria perusahaan. Strategi pengembangan sumber daya manusia yang sedang dikembangkan oleh negara maju dan kecenderungan di masa mendatang adalah mengeksploitasi potensi sumber daya manusia yang dihubungkan dengan aplikasi ilmu pengetahuan dan teknologi, perilaku manusia, kerja karyawan, dalam rangka meningkatkan prestasi bisnis atau organisasi (Riflan, 2017).

Setiap organisasi memiliki ciri khas yang membedakannya dengan organisasi lain. Ciri khas ini menjadi identitas bagi organisasi. Ciri khas inilah yang dinamakan budaya organisasi. Budaya organisasi mengandung nilai-nilai yang harus dipahami, dijiwai, dan dipraktikkan bersama oleh semua individu/kelompok yang terlibat didalamnya. Budaya berhubungan dengan bagaimana organisasi membangun komitmen mewujudkan visi, memenangkan hati pelanggan, 
memenangkan persaingan dan membangun kekuatan perusahaan. Budaya organisasi dibentuk dari filosofi organisasi dan nilai-nilai yang dianut oleh sumber daya manusia di dalam organisasi, akan tetapi peran dari pimpinan atau top manajemen sangat besar dalam pembentukan budaya organisasi. Budaya yang ada pada suatu organisasi akan mempengaruhi cara pekerjaan dilakukan dan cara para pegawai berperilaku serta menyebabkan para pekerja memiliki cara pandang yang sama dalam melaksanakan aktivitas pekerjaan. Budaya organisasi juga akan memiliki dampak pada efisiensi dan efektivitas organisasi. Menurut (Noor, 2015) budaya organisasi merupakan hubungan antara nilai, kebiasaan dan tradisi yang di terapkan kepada cara kerja, sehingga menjadi pembeda dari organisasi lain.

Fleksibilitas kerja seringkali dihubungkan dengan perluasan deregulasi dalam kerja. Menjadi fleksibel diartikan sebagai seseorang yang memiliki kemampuan untuk menjadi berbeda sesuai dengan apa yang dibutuhkan, ide ini mencerminkan kemampuan untuk tetap dapat beroperasi dalam kondisi yang selalu berubah, baik ketika perubahan tersebut dapat diprediksi maupun tidak (Wahyuni, 2014).

Umpan balik merupakan suatu konsekuensi sebagai karyawan yang diberikan perusahaan untuk menyelesaikan aktivitas pekerjaannya, agar informasi tentang keefektifan kerjanya dapat tersampaikan dan perbaikan keluhan pelanggan oleh jasa yang telah diberikan kepada pelanggan dapat ditangani dengan cepat oleh perusahaan (Arianto, 2017).

Prestasi kerja adalah pencapaian karyawan terhadap syarat-syarat pekerjaan. Dengan kata lain, prestasi kerja merupakan proses pengukuran kinerja karyawan atas pelaksanaan kerjanya dari segala aspek (Muhammad Calvin CAPNARY, Riani RACHMAWATI, 2018). Permintaan pelanggan yang semakin berekspektasi mendorong untuk membuat perusahaan mengembangkan karyawan agar lebih berprestasi dalam bekerja (Noor, 2015).

Salah satu perusahaan penyedia jasa aplikasi trasportasi yang fenomenal adalah PT.Go-Jek Indonesia. Perusahaan ini bergerak dalam bidang jasa transportasi dengan aplikasi berbasis internet Perusahaan ini didirikan oleh Nadiem Makarim pada tahun 2011 di Jakarta yang pada awalnya hanya melayani pemesanan lewat panggilan telepon saja, kemudian pada awal tahun 2015 meluncurkan aplikasi mobile bernama Go-Jek. Ratusan ribu pemilik kendaraan motor maupun mobil telah bergabung menjadi mitra driver Gojek.

Melihat pentingnya pengembangan sumberdaya manusia dalam era teknologi ini, penulis tertarik untuk melakukan penelitian dengan judul budaya organisasi, fleksibilitas kerja, dan umpan balik (feedback) terhadap prestasi kerja transportasi ojek online (Gojek). Gojek dipilih karena merupakan penyedia jasa aplikasi transportasi umum dengan driver terbanyak di Palembang. 


\section{LANDASAN TEORI}

Menurut (Imron, 2019) prestasi kerja merupakan hak yang didapat seseorang maupun kelompok setelah tanggung jawab dan wewenangnya masing-masing dijalankan, searah dengan tujuan perusahaan dengan aturan tidak melanggar hukum, moral dan etika.

Fleksibilitas kerja adalah kerja yang fleksibel dalam artian lain, jam kerja dapat diringkas dengan kemampuan anggota organisasi untuk merubah durasi kerja sesuai dengan lokasi kerja

dan kemampuan untuk memenuhi jadwal kerja yang disediakan oleh organisasi.(Muhammad Calvin Capnary, Riani Rachmawati, 2018)

Umpan balik pelanggan didefinisikan sebagai komunikasi pelanggan mengenai suatu produk atau layanan.(Nasr et al., 2014)

Budaya organisasi adalah keyakinan tradisi oleh masing-masing anggota organisasi yang dikembangkan dan diterapkan pada cara kerja, untuk mengatasi masalah yang akan datang.(Imron, 2019).

\section{Kerangka penelitian}

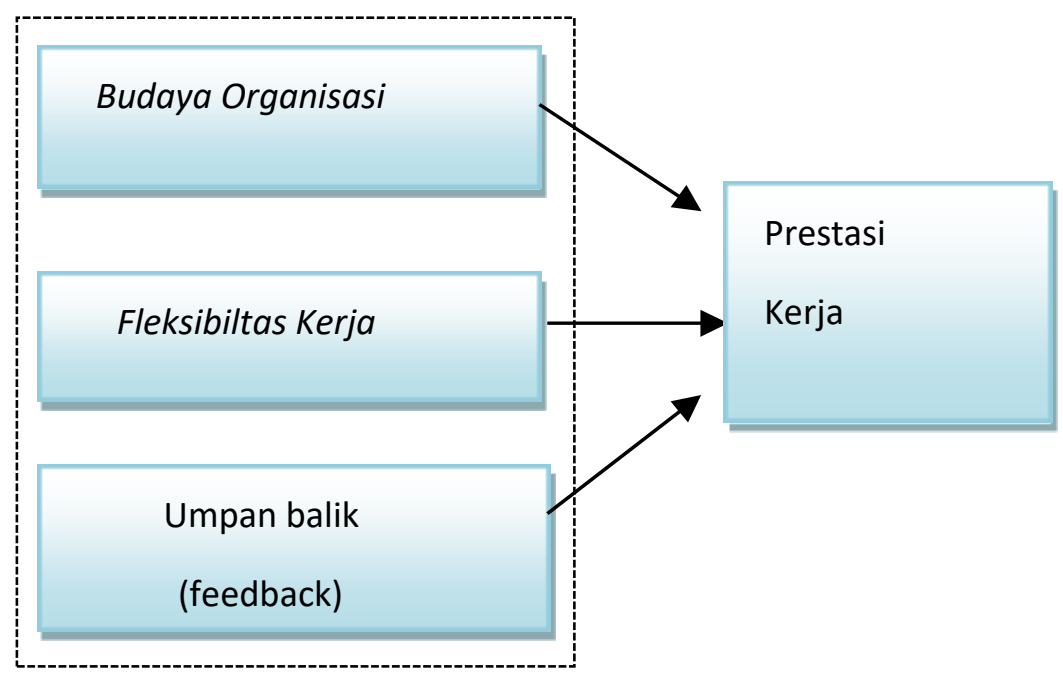

\section{METODE PENELITIAN}

Desain penelitian ini termasuk jenis penelitian survey, yaitu penelitian yang mengambil sampel dari satu populasi dan menggunakan kusioener sebagai alat pengumpul data yang pokok. Pada umumnya unit analisis dalam penelitian survey adalah individu (Singarimbun, 1995). Metode penelitian survey merupakan metode yang memberikan pertanyaan terstruktur kepada sampel dari populasi dan dirancang untuk memperoleh informasi dari responden (Widayat dan Amirullah, 2002). Unit analisa dalam penelitian ini adalah driver Gojek di Palembang. 
Dalam penelitian ini terdapat dua jenis variabel, yaitu variabel bebas berupa budaya organisasi, fleksibilitas kerja, dan umpan balik (feedback) dan variabel terikat berupa prestasi kerja driver Gojek. Populasi yang ditetapkan pada penelitian ini adalah seluruh driver Gojek di Palembang. Total populasi pada tahun 2020 ini adalah 435 orang. Sampel ditarik berdasarkan teknik pengambilan sampel accidental sampling (Indrianto, 1999) dan untuk itu dari total populasi 435 orang diambil 25\%nya menjadi 110 orang yang akan diteliti (Arikunto, Suharsini; 1993). Data diperoleh dari penyebaran kuesioner yang dilakukan dalam bulan Januari Februari tahun 2020.

Teknik analisis data menggunakan uji determinasi $\left(R^{2}\right)$, regresi linear berganda, uji asumsi klasik, uji F (simultan), uji t (parsial).

\section{TEMUAN DAN PEMBAHASAN}

\section{Uji $R^{2}$}

Hasil $\mathrm{R}^{2}$ menunjukkan bahwa pengaruh variabel budaya organisasi, fleksibilitas kerja, dan umpan balik (feedback) terhadap variabel prestasi kerja transportasi ojek online (Gojek) 46,2\%. Tersisa 53,8\% dipengaruhi variabel lain yang tidak diteliti dalam penelitian ini.

\section{Uji Regresi Linear Berganda}

Tabel 1. Hasil Uji Regresi Linear

\begin{tabular}{lcccc}
\hline \multicolumn{1}{c}{ Variabel } & \multicolumn{2}{c}{ Unstandardized Coefficients } & t & Sig \\
\hline Constant & B & Std. Eror & & 0.321 \\
Budaya Organisasi & 2.310 & 3.129 & 1.092 & 0.000 \\
Fleksibiltas Kerja & 0,145 &, 069 & 4,461 & 0.002 \\
Umpan balik (feedback) & 0,256 &, 096 & 3.221 & 0.000 \\
\hline
\end{tabular}

Sumber : Pengolahan data 2020

Dari hasil pengolahan data diatas dapat disusun persamaan regresi linearnya sebagai berikut :

$\mathrm{Y}=2,310+0,145 \mathrm{X}_{\mathrm{bo}}+0,256_{\mathrm{fk}}+0,428 \mathrm{X}_{\mathrm{ub}}+\mathrm{e}$

Keterangan:

1. Nilai konstanta $=2,310$, artinya variabel fleksibilitas kerja, umpan balik (feedback) dan budaya organisas secara positif berpengaruh terhadap prestasi 
kerja sebesarp2,310.

2. Nilai koefisien variabel budaya organisasi $=0,145$, artinya ketika variabel budaya organisasi mengalami peningkaatan sebesar satu satuan, sementara variabel lainnya tetap, maka variable prestasi kerja naik 0,145.

3. Nilai koefisien variabel fleksibilitas kerja $=0,256$, artinya ketika variabel fleksibilitas kerja mengalami peningkatan sebesar satu satuan, sementara variabel lainnya tetap, maka variabel prestasi kerja akan naik 0,256.

4. Nilai koefisien variabel umpan balik $($ feedback $)=0,428$, artinya ketika variabel umpan balik (feedback) mengalami peningkatan sebesar satu satuan, sementara variabel tetap maka variable prestasi kerja naik 0,428 .

\section{Uji Multikolinearitas}

Hasil uji multikolinearitas, pada model regresi tidak menunjukkan adanya multikolinearitas. Diperoleh dari tolerance value $>0,10$ pada VIF kurang dari 10.

\section{Uji Heteroskedastisitas}

Uji Glejser, pada model regresi tidak menunjukkan adanya heteroskedastisitas dan nilai probabilitas signifikansi pada variabel independen $>5 \%$.

\section{Uji F}

Uji yang digunakan mengetahui pengaruh budaya organisasi, fleksibilitas kerja, dan umpan balik (feedback), terhadap prestasi kerja transportasi ojek online (Gojek) (uji simultan).

Hasil analisis data yang telah didapatkan 24,421, dikarenakan Fhitung $>$ Ftabel $(24,421>2,70)$ dan signifikansi 0,000 < 0,05 artinya fleksibilitas kerja, umpan balik (feedback) dan budaya organisasi secara simultan dan signifikan berpengaruh terhadap prestasi kerja transportasi ojek online (Gojek).

\section{Ujit}

Uji yang dipergunakan dalam menganalisis, variabel independen masing-masing mempunyai pengaruh pada variabel dependen. Hasil analisis data yaitu:

1. Budaya Organisasi

Nilai ttabel $1,985<$ thitung4,461 dan signifikannya $0,000<0.05$ artinya $\mathrm{H}_{\mathrm{o}}$ ditolak, jadi budaya organisasi berpengaruh secara positif dan signifikan terhadap prestasi kerja transportasi ojek online (Gojek) .

2. Fleksibilitas Kerja

Nilai ttabel 1,985 < thitung 3,221, signifikannya 0,002<0,05. Artinya $H_{o}$ ditolak, jadi fleksibilitas kerja secara positif dan signifikan berpengaruh terhadap variabel prestasi kerja transportasi ojek online (Gojek).

3. Umpan Balik (feedback) 
Nilai ttabel 1,985< thitung4,015 nilai signifikan memiliki nilai 0,000<0,05. Maka Ho ditolak, jadi variabel umpan balik (feedback) secara positif dan signifikan berpengaruh terhadap prestasi kerja transportasi ojek online (Gojek).

Penelitian ini bertujuan untuk mengetahui pengaruh budaya organisasi, fleksibilitas kerja dan umpan balik terhadap prestasi keja driver ojek online (Gojek) di Palembang. Berdasarkan penelitian tingkat pengaruh nilai budaya organisasi, fleksibilitas kerja dan umpan balik secara 6 bersama-sama terhadap Prestasi Kerja menunjukkan hasil analisis bahwa nilai budaya organisasi, fleksibilitas kerja dan umpan balik memiliki pengaruh terhadap Prestasi Kerja. Nilai R sebesar 0,462 menunjukkan bahwa tingkat pengaruh nilai budaya organisasi dan fleksibilitas kerja dan umpan balik secara bersama-sama terhadap prestasi kerja.

Hal ini juga ditunjukkan dengan besarnya presentase pengaruh nilai budaya organisasi, fleksibilitas kerja dan umpan balik secara bersama-sama terhadap prestasi kerja yaitu sebesar 46,2\%. Sisanya sebesar 53,8\% dipengaruhi faktor lain diluar yang diteliti. Secara positif dan signifikan budaya organisasi berpengaruh pada prestasi kerja transportasi ojek online (Gojek) karena budaya organisasi dapat menciptakan motivasi bagi driver dan membantu driver untuk memberikan kinerja terbaiknya. Hasil penelitian ini menguatkan penelitian serupa.(Kusuma, 2019) Secara positif dan signifikan fleksibilitas kerja berpengaruh terhadap prestasi kerja. Hasil itu membuktikan bahwa semakin tinggi fleksibilitas kerja, maka akan semakin tinggi prestasi kerja transportasi ojek online (Gojek). Fleksibilitas kerja dapat berpengaruh pada prestasi kerja transportasi ojek online (Gojek) karena kebijakan perusahaan yang memfasilitasi karyawan untuk meringkas dan merubah durasi kerja mereka sesuai lokasi kerja (diluar tempat kerja) sehingga durasi kerja dari perusahaan terpenuhi tanpa mengurangi jam kerja yang telah diberikan oleh perusahaan.

Artinya apabila fleksibilitas kerja yang ada semakin bagus, maka prestasi kerja akan meningkat. Penelitian ini sejalan dengan penelitian (Riflan, 2017). Umpan balik (feedback) memiliki pengaruh positif dan signifikan terhadap prestasi kerja. Umpan balik (feedback) dapat membantu mengurangi kesenjangan kinerja bawahan, antara kinerja actual dengan standar kinerja yang diinginkan atasan. Hasil penelitian ini menguatkan penelitian (Candra \& Indiastuti, 2019).

\section{KESIMPULAN DAN SARAN}

Budaya organisasi (X1) berpengaruh terhadap prestasi kerja. Ini berarti bahwa eksistensi budaya pada driver ojek online (Gojek) sangat dibutuhkan, sehingga perlu diperhatikan. Fleksibilitas kerja (X2) berpengaruh pada prestasi kerja transportasi ojek online (Gojek). Ini berarti bahwa fleksibilitas kerja pada driver ojek online (Gojek) sangat dibutuhkan, sehingga perlu diperhatikan. Umpan balik (feedback) (X3) berpengaruh pada prestasi kerja transportasi ojek online (Gojek). Ini 
berarti bahwa umpan balik kerja pada driver ojek online (Gojek) sangat dibutuhkan, sehingga perlu diperhatikan. Budaya organisasi, fleksibilitas kerja dan umpan balik memiliki pengaruh secara simultan terhadap prestasi kerja.

\section{DAFTAR PUSTAKA}

Arianto, J. P. S. (2017). Pengaruh Customer Satisfaction, Brand Trust, dan Customer Feedback Terhadap Customer Loyalty Pada Perusahaan Mobil Suzuki. Jurnal Al-Qardh, 1(1), 50-60. https://doi.org/10.23971/jaq.v1i1.629

Candra, S. A., \& Indiastuti, D. L. (2019). Pengaruh Perilaku Mencari Umpan Balik Terhadap Kinerja Dengan Variabel Moderasi Keadilan Prosedural. Jurnal Ekonomi, Bisnis, Dan Akuntansi (JEBA), 21(1).

Imron, S. (2019). Pengaruh Gaya Kepemimpinan, Kerjasama Tim, Dan Budaya Organisasi Terhadap Prestasi Kerja Dan Dampaknya Kepada Kinerja PEGAWAI Imron. Jurnal Ekonomi Dan Manajemen, 5(1), 64-83.

Kusuma, A. (2019). Pengaruh Budaya Organisasi Dan Kemampuan Kerja Individu Terhadap Prestasi Kerja Pada Bank Bjb Syariah Cabang Cirebon. Value: Jurnal Manajemen Dan Akuntansi, 12(2), 95-107. https://doi.org/10.32534/jv.v12i2.479

Muhammad Calvin Capnary, Riani Rachmawati, I. A. (2018). The influence of flexibility of work to loyalty and employee satisfaction mediated by work life balance to employees with millennial generation background in indonesia startup companies. Business: theory and practice, 19(1), 217-227.

Nasr, L., Burton, J., Gruber, T., \& Kitshoff, J. (2014). Exploring the impact of customer feedback on the well-being of service entities ATSR perspective. Journal of Service Management, 25(4), 531-555. https://doi.org/10.1108/JOSM-01-20140022

Noor, H. M. T. (2015). Analisis pengaruh iklim organisasi dan budaya organisasi terhadap prestasi kerja karyawan pada pt. Mustika

SEMBULUH DI SAMPIT. Jurnal Terapan Manajemen Dan Bisnis, 1(1), 28-38.

Riflan, M. (2017). Pengaruh Tanggungjawab, Fleksibilitas, Standar, Komitmen Tim, Kejelasan, Penghargaan, Dan Gaya Kepemimpinanterhadap Prestasi Kerja Pegawai Honorer Sekretariat Dprd Kabupaten Parigi Moutong. 05(02), 1-6.

Wahyuni, S. (2014). Faktor-faktor yang mempengaruhi fleksibilitas tenaga kerja kontrak dan paruh waktu pada umkm di jawa tengah. 17(2), 139- 151. 